\title{
Effect of platelet-rich plasma concentrations on the proliferation of periodontal cells: An in vitro study
}

\author{
Sara Tavassoli-Hojjati ${ }^{1}$, Mandana Sattari ${ }^{2}$, Tayebeh Ghasemi ${ }^{3}$, Rahil Ahmadi ${ }^{4}$, \\ Abbas Mashayekhi ${ }^{5}$
}

Correspondence: Dr. Rahil Ahmadi

Email: rahilsh@yahoo.com

\begin{abstract}
'Department of Pediatric Dentistry, Dental School, Islamic Azad University, Tehran Branch, Tehran, Iran, 2Department of Immunology, Medical School, Shahid Beheshti University of Medical Sciences, Tehran, Iran, ${ }^{3}$ Department of Oral and Maxillofacial Surgery, Tehran University of Medical Sciences, Tehran, Iran, ${ }^{4}$ Department of Pediatric Dentistry, Dental School, Shahed University, Tehran, Iran,

${ }^{5}$ Department of Dermatology, Medical School, Islamic Azad University, Markazi, Iran
\end{abstract}

\section{ABSTRACT}

Objective: The purpose of this study was to evaluate the effect of different concentrations of platelet-rich plasma (PRP) on the proliferation of undifferentiated periodontal ligament (PDL) fibroblasts. Materials and Methods: The undifferentiated PDL fibroblasts were obtained from two healthy human premolar teeth and cultured in Dulbecco's modified Eagle's medium. Cell wells were divided into five groups. Experimental groups received $0.1 \%, 5 \%$, or $50 \%$ PRP; the positive and negative control groups were cultured in fetal bovine serum (FBS) $12 \%$ and in a medium without FBS $12 \%$, respectively. The plates were incubated at $37^{\circ} \mathrm{C}$ for 1 , 2, 3, 4, and 7 days. PDL cell viability was assessed by 3-(4,5-dimethylthiazol-2-yl)-2,5-diphenyltetrazolium bromide proliferation assay. Statistical analysis of the data was accomplished using repeated measure ANOVA and Tukey's test. $P<0.05$ was considered statistically significant. Results: The 5\% PRP had the greatest effect on undifferentiated fibroblast proliferation, which was significant on the $3^{\text {rd }}$ day. There was no significant difference between $0.1 \%$ PRP and positive control during the first 3 days. The group with $50 \%$ PRP presented significantly lower proliferation, compared to other experimental and control groups. Conclusions: It may be concluded that the growth-stimulating effect of PRP is dose dependent with the best results in low concentrations.

Key words: Avulsion, cell culture, cell proliferation, periodontal ligament cell, platelet-rich plasma

\section{INTRODUCTION}

Tooth avulsion is one of the most complex modalities of traumatic dental injuries, which corresponds to $0.5 \%-16 \%$ of all traumatic accidents of permanent dentition. ${ }^{[1,2]}$ It is commonly associated with serious complications due to severe damage to the periodontal ligament (PDL). ${ }^{[3]}$ In spite of all clinical efforts which have been made to avoid the root resorptions, the frequency

\begin{tabular}{|l|l|}
\hline \multicolumn{2}{|c|}{ Access this article online } \\
\hline Quick Response Code: \\
\hline
\end{tabular}

of PDL healing after replantation of the avulsed teeth remains as low as $20 \%-25 \% .{ }^{[2]}$ The treatment prognosis of teeth with avulsion widely depends on some intrinsic and extrinsic factors, of which compromised PDL cell viability particularly plays an important role leading to undesired outcomes. ${ }^{[1]}$ According to the results of the various investigations about the impact of vitality of

This is an open access article distributed under the terms of the Creative Commons Attribution-NonCommercial-ShareAlike 3.0 License, which allows others to remix, tweak, and build upon the work non-commercially, as long as the author is credited and the new creations are licensed under the identical terms.

For reprints contact: reprints@medknow.com

How to cite this article: Tavassoli-Hojjati $\mathrm{S}$, Sattari M, Ghasemi T, Ahmadi R, Mashayekhi A. Effect of platelet-rich plasma concentrations on the proliferation of periodontal cells: An in vitro study. Eur J Dent 2016;10:469-74.

DOI: $10.4103 / 1305-7456.195165$ 
PDL cells on the survival of the exarticulated teeth, there are no promising outcomes of the current treatment protocols. $^{[1-4]}$

Histologically, after replantation of a traumatized tooth, a coagulum is formed which initiates the wound healing procedure, ${ }^{[2]}$ a complex mechanism compiling of four distinct phases: homeostasis, inflammation, proliferation, and remodeling ${ }^{[2,5]}$ All of these stages are regulated and controlled by cellular and humoral elements, starting with the impact of platelets in the homeostasis process. ${ }^{[2,6]}$

Previous researches revealed the significant role of various growth factors and cytokines associated with wound repair progression. ${ }^{[7-9]}$ Released growth factors bind to the receptors of target cells (fibroblasts, osteoblasts, mesenchymal stem cells) and activate intracellular signals leading to cellular proliferation, collagen synthesis, and matrix formation as essential components of the wound healing. ${ }^{[2,10,11]}$ In tissue injuries with blood vessel disruption, platelets adhere to the exposed collagen proteins and initiate the secretion of numerous mediators. ${ }^{[2,10,12]}$ Growth factors released by platelets such as platelet-derived growth factors (PDGFs) and transforming growth factor- $\beta$ (TGF- $\beta$ ), as well as insulin-like growth factor-I, are mitogenic proteins associated with collagen synthesis, bone formation, and early wound closure. ${ }^{[2,10]}$

According to the outstanding and crucial impacts of growth factors associated with wound repair, there is currently a great deal of interest in implementing potential origins of these elements either recombinant growth mediators or factors with autogenous origin such as platelet-rich plasma (PRP). ${ }^{[13]}$ PRP is defined as a portion of high concentrated platelets (3-5-fold) in a small volume of plasma. ${ }^{[3,14]}$ Accumulation of platelets in PRP results in increased levels of growth factors for a longer period compared to the whole blood clots of similar volumes. ${ }^{[15-17]}$ Thus, applying PRP in patients undergoing osseous or periodontal regeneration is recommended on the premise that the large population of platelets in PRP releases huge amounts of essential factors, and it is biologically safe and inexpensive compared to recombinant allogeneic or xenogeneic preparations. ${ }^{[2,13,16,18]}$

However, although promising results are reported by many in vivo or in vitro investigations on bone or PDL repair, some others demonstrate a retardation of tissue regeneration due to PRP treatment. One of the reasons explaining the disparity of reported findings may be due to the different PRP concentrations and thus various amount of growth factors and diverse target cells in the above-mentioned studies, ${ }^{[2]}$ which led to conflicting recommendations. ${ }^{[13,14,19-21]}$ Therefore, the purpose of this in vitro study was to examine the impact of different PRP concentrations on the proliferation of undifferentiated PDL cells.

\section{MATERIALS AND METHODS}

This research was approved by the Institutional Review Board and Ethics Committee of Shahed University (4/418), Tehran, Iran, and informed consent was obtained from the adult contributor and the parents of the minor precipitant.

\section{Cell culture}

Human PDL cells were obtained from two clinically sound premolars extracted for orthodontic reasons from a 14-year-old systematically and periodontally healthy patient.

The freshly extracted teeth were immersed in Dulbecco's modified Eagle medium (DMEM; Gibco, Glasgow, UK), supplemented with $1 \%$ penicillin/ streptomycin, $1 \%$ gentamycin, $12 \%$ fetal bovine serum (FBS), and $0.5 \%$ amphotericin B. Following rinsing with phosphate-buffered saline for residual blood elimination, PDL tissues were collected from the mid-third of the teeth root with a \#15 scalpel under sterile conditions. The detached tissues were transferred into $25 \mathrm{~cm}^{2}$ culture dishes (Nunc, Roskilde, Denmark). The explants were incubated with DMEM, 12\% FBS, penicillin $50 \mu \mathrm{g} / \mathrm{ml}$, and streptomycin $50 \mu \mathrm{g} / \mathrm{ml}$ at $37^{\circ} \mathrm{C}$ in the presence of $5 \%$ of $\mathrm{CO}_{2}$ in air for 3 weeks. The culture medium was renewed every 3 days until cells reached confluence. The cells from passages 3 to 6 were used in this study. Cells were seeded in five 24 -well plates at a density of $5 \times 10^{4}$ cells/well, corresponding to each of the experimental time courses (1, 2, 3, 4, and 7 days). After $24 \mathrm{~h}$, each group of cells was exposed to PRP in one of the examined concentrations $(0.1 \%, 5 \%$, and $50 \%)$. No culture medium and FBS $12 \%$ served as negative and positive controls, respectively.

\section{Platelet-rich plasma preparation}

PRP was collected and prepared immediately before application on the cultured cells. Twenty milliliters venous blood from a healthy donor was collected in acid-citrate-dextrose solution formula A collection tube (BD, United States). The whole blood was initially 
centrifuged at $2400 \mathrm{rpm}$ for $10 \mathrm{~min}$ to separate red blood cell (RBC) portion from PRP and platelet-poor plasma. The upper layer of RBC fraction and PRP portion were removed and centrifuged again at $3600 \mathrm{rpm}$ for $15 \mathrm{~min}$, and PRP was extracted in a plain collection tube (BD, United States). ${ }^{[22]}$ PRP was activated by adding calcium chloride $\left(\mathrm{CaCl}_{2}\right)$ and immediately diluted with DMEM, resulting in concentrations of $0.1 \%, 5 \%$, and $50 \%$.

\section{3-(4,5-dimethylthiazol-2-yl) -2,5-diphenyltetrazolium bromide (cell viability) assay}

The 3-(4,5-dimethylthiazol-2-yl)-2,5-dipheny ltetrazolium bromide (MTT) assay was conducted to assess the cell viability and proliferation ${ }^{[23]}$ after each of the experimental time periods in all of the treatment mediums. Cells were incubated with $50 \mu \mathrm{l}$ of MTT solution (Sigma-Aldrich, USA) for $4 \mathrm{~h}$ at $37^{\circ} \mathrm{C}$. The MTT media were then discarded and formazan crystals were dissolved by adding $50 \mu \mathrm{l}$ of dimethyl sulfoxide (Sigma-Aldrich, USA) to each well. ${ }^{[23]}$ The spectrophotometric absorbance of each sample recorded at $570 \mathrm{~nm}$ in an ELISA reader (Anthos Labtec Instruments, Austria) was reported as optical density (OD). ${ }^{[2,24]}$ The mean cell viability was expressed as the percentage of the mean experimental OD values to the values of the control (OD value of the control at the time $=0$ was 0.89 ).

\section{Statistical analysis}

One-way ANOVA and post hoc Tukey's test were used to evaluate differences of the mean cell viability values among various treatments. A $P<0.05$ was considered statistically significant.

\section{RESULTS}

In the present study, the effect of various concentrations of PRP and two groups without PRP (control groups) on the cells vitality at five time intervals was assessed using an MTT method.

The average platelet count of the donor was 282,000 platelets/ $\mu \mathrm{l}$, while the mean platelet count of the PRP preparation was 1,194,000 platelets/ $\mu 1$.

The mean viability of different PRP and control groups on days 1, 2, 3, 4, and 7 is demonstrated in Table 1 , revealing a significant difference among the samples at various time intervals $(P<0.001)$.

All groups showed a progressive proliferation during the first $72 \mathrm{~h}$, with their peak on the $3^{\text {rd }}$ day. However,

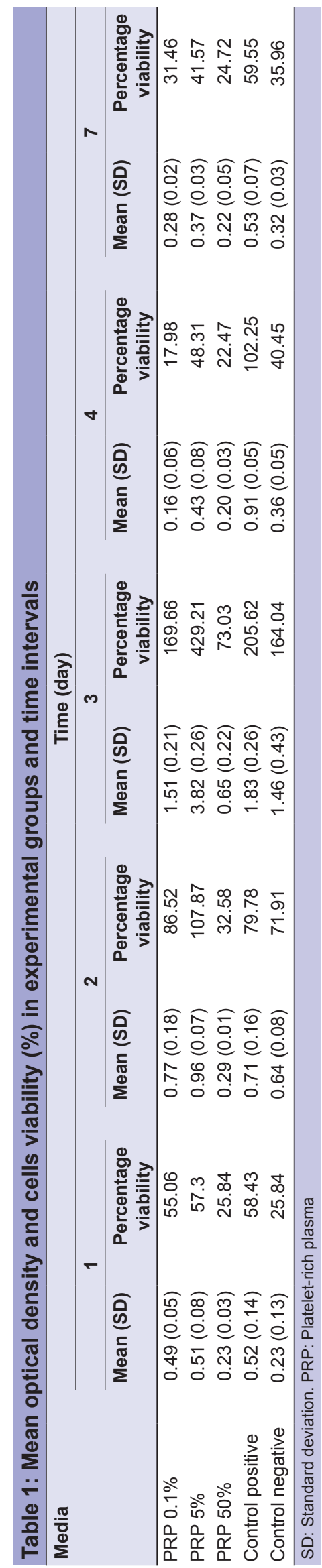


afterward, a decrease in cell vitality occurred on the $4^{\text {th }}$ and $7^{\text {th }}$ days in all experimental and control groups [Figure 1].

No significant difference was found between the positive control and $0.1 \%$ PRP during the first 3 days $(P>0.05)$. We observed the most promising results during the $72 \mathrm{~h}$ with the $5 \% \mathrm{PRP}$ concentration. Although in comparison with $12 \%$ FBS group, this was insignificant on the $1^{\text {st }}$ day $(P>0.05)$, a statically significant difference on the $2^{\text {nd }}$ and $3^{\text {rd }}$ days was seen $(P<0.05$ and $P<0.001$, respectively). A significant difference between the $5 \%$ and $0.1 \%$ PRP groups was found during the $3^{\text {rd }}$ and $4^{\text {th }}$ days [Table 2].

As revealed in Table 1, 50\% PRP decreased the proliferation rate during all the five time intervals. This was even significant after the $1^{\text {st }}$ day compared with control group without $12 \%$ FBS $(P<0.05)$, presenting a suppressing effect on the cell proliferation [Table 2].

\section{DISCUSSION}

During the first step of the PDL regeneration, a temporary matrix of fibrinogen, fibronectin, and fibrin is formed at the site of the injury to minimize cell loss. Platelet-released growth factors, particularly PDGF- $\beta$, promote cell proliferation, migration, adherence, and their spreading on the extracellular matrix. ${ }^{[2,14,21]}$ PRP has been introduced as an autologous source of platelets in different aspects of wound healing in dentistry, delivering increased levels of growth factors. ${ }^{[15]}$ However, due to different preparation techniques, various cell types, and different platelet concentrations, there is variety of recommendations concerning its usage. ${ }^{[10,15,20,21]}$

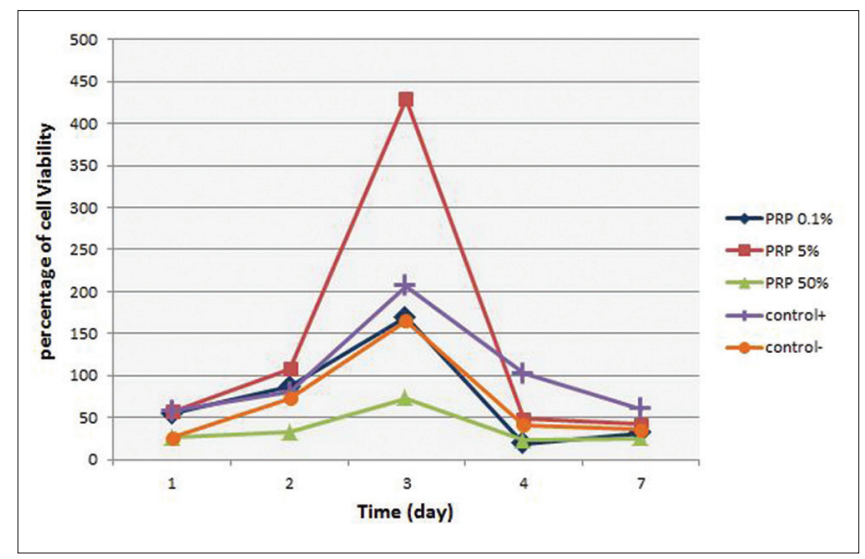

Figure 1: Periodontal ligament cell viability according to the experimental media and time intervals
A concentration of $1,000,000$ platelets $/ \mu 1$ has been recommended as the working definition of PRP. Since the normal range of platelets in the whole blood of healthy individuals varies from 140,000 to 400,000 platelets/ $\mu$, this means a $3-5$-fold increase over the baseline concentration. ${ }^{[15,16]}$ We found 282,000 and 194,000 platelets / $\mu 1$ in whole blood and PRP sample, respectively, demonstrating a 4.2-fold enrichment, which was in accordance with previous literature. ${ }^{[15,16,25]}$

At present, we found that PRP enhanced PDL cell proliferation, yet in a dose-dependent manner, with $5 \%$ concentration being most effective. A dose-related response was also observed by Arikan et al., however, with different activation methods and PRP concentrations. They have also delivered PRP into the cell cultures for several times; conversely, in our research, a onetime PRP delivering was applied to mimic the clinical conditions. ${ }^{[5]}$

We found that both $0.1 \%$ and 5\% PRP concentrations encouraged cellular proliferation although 5\% PRP significantly had a greater stimulating impact. The $50 \%$ concentration adversely affected cell vitality. Creeper et al. also reported a cytotoxic effect in implementing maximum PRP concentrations (100\%); however, they suggested $50 \%$ concentration as the most proliferative PRP enrichment for PDL cells. ${ }^{[26]}$ Choi et al. examined the effect of PRP in various concentrations on the bone formation within the PRP-treated bone grafts. They suggested that a dilution of PRP to a level of $0.5 \%-5 \%$ would stimulate osteoblastic proliferation and might act as a mitogen on alveolar bone cells. ${ }^{[23]}$

Our results revealed an enhancement of cellular proliferation when PDL cells were cultured in a medium supplemented with low PRP density. This finding may be explained by the fact that as cell surface receptors are completely invaded by a specific growth factor, the remaining unbounded growth mediators have no additional impact; on the contrary, in high concentrations, an inhibitory effect on cell functions may be induced. ${ }^{[17]}$ Han et al. reported that the most stimulatory effect of PRP on PDL cells may be exerted by a concentration of $50-100 \mathrm{ng} / \mathrm{ml}$ of TGF- $\beta .{ }^{[27]}$ Thus, the optimal concentration of the platelets should be selected according to the target cells as a determinant element. ${ }^{[17]}$

As stated previously, more than $2 / 3$ of the essential growth factors are released within 10 min and almost 


\begin{tabular}{|c|c|c|c|c|c|}
\hline Time (day) & Group & PRP $0.1 \%(P)$ & PRP 5\% $(P)$ & PRP $50 \%(P)$ & Control positive $(P)$ \\
\hline \multirow[t]{4}{*}{1} & PRP 5\% & $0.998^{*}$ & & & \\
\hline & PRP 50\% & $0.012^{* *}$ & $0.07^{*}$ & & \\
\hline & Control positive & $0.984^{*}$ & $1^{*}$ & $0.005^{* *}$ & \\
\hline & Control negative & $0.024^{* *}$ & $0.014^{\star *}$ & $1^{*}$ & $0.01^{* *}$ \\
\hline \multirow[t]{4}{*}{2} & PRP 5\% & $0.167^{*}$ & & & \\
\hline & PRP $50 \%$ & $<0.001^{* *}$ & $<0.001^{* *}$ & & \\
\hline & Control positive & $0.946^{*}$ & $0.046^{\star *}$ & $0.001^{* *}$ & \\
\hline & Control negative & $0.544^{*}$ & $0.009^{* *}$ & $0.005^{\star *}$ & $0.918^{*}$ \\
\hline \multirow[t]{4}{*}{3} & PRP 5\% & $<0.001^{* *}$ & & & \\
\hline & PRP $50 \%$ & $0.005^{* *}$ & $<0.001^{* *}$ & & \\
\hline & Control positive & $0.538^{*}$ & $<0.001^{* *}$ & $<0.001^{\star *}$ & \\
\hline & Control negative & $0.998^{*}$ & $<0.001^{* *}$ & 0.01 & $0.38^{*}$ \\
\hline \multirow[t]{4}{*}{4} & PRP 5\% & $<0.001^{\star *}$ & & & \\
\hline & PRP $50 \%$ & $0.8^{*}$ & $<0.001^{* *}$ & & \\
\hline & Control positive & $<0.001^{* *}$ & $<0.001^{* *}$ & $<0.001^{* *}$ & \\
\hline & Control negative & $0.001^{* *}$ & $0.4^{*}$ & 0.006 & $<0.001^{\star *}$ \\
\hline \multirow[t]{4}{*}{7} & PRP 5\% & $0.07^{*}$ & & & \\
\hline & PRP $50 \%$ & $0.368^{*}$ & $0.002^{* *}$ & & \\
\hline & Control positive & $<0.001^{* *}$ & $0.001^{* *}$ & $<0.001^{* *}$ & \\
\hline & Control negative & $0.747^{\star}$ & $0.465^{\star}$ & $0.05^{\star *}$ & $<0.001^{* *}$ \\
\hline
\end{tabular}

$100 \%$ in the $1^{\text {st }} \mathrm{h}$ after platelet activation. However, additional grow th factors are produced and released several days after losing their vitality, describing their promoting effect over time, as observed with the high stimulated cell proliferation at the $3^{\text {rd }}$ day in the present research. ${ }^{[16,26]}$ Nevertheless, we found a significant reduction in all cultured groups after this time. It may be due to the fact that following the high proliferation rate during the first $72 \mathrm{~h}$, the number of cells is increased leading to a shortage of nutritional sources and aggregation of waste materials. ${ }^{[5]}$

PRP preparation protocols rely on a variety of activators such as bovine or autologous thrombin or $\mathrm{CaCl}_{2}$. All of them initiate the clotting cascade and precipitation of the fibrin scaffold. However, bovine thrombin has demonstrated several side effects in human or animal investigations. Hemorrhage, thrombosis, raised antibody levels against coagulation proteins are some of the adverse effects of exogenous thrombin. ${ }^{[15]}$ As no side effects were reported in association with $\mathrm{CaCl}_{2}$ as PRP activator, we have preferred its usage. $\mathrm{CaCl}_{2}$ leads to the conversion of prothrombin to thrombin as the first step of clot formation and healing process. ${ }^{[15,28,29]}$

One of the complications with the clinical use of PRP in treating traumatized teeth is the young age of injured patients ranging mostly from 7 to 9 years, with a generally still low cooperation for being subjected to blood drawing procedure. ${ }^{[2]}$ However, performing venipuncture by a trained surgeon and using behavior management techniques may decrease the inconvenience of the treatment.

We believe that final prognosis of a traumatized tooth particularly suffered from exarticulation is affected by multiple influencing factors other than those acting on in vitro settings, changing the environment of PDL regeneration. Thus, we suggest further in vivo investigations of PRP-treated avulsed teeth with follow-up radiographs to evaluate the clinical significance of these results.

\section{CONCLUSIONS}

Under the condition of this in vitro study, it can be concluded that:

1. Different PRP concentrations may influence PDL regeneration

2. The vitality and proliferation of PDL cells are stimulated by low concentrations of PRP (5\%) and are suppressed by high concentrations (50\%), suggesting a dose-related response.

\section{Financial support and sponsorship}

This work was supported by a grant from the Research Committee of the Shahed University, Tehran, Iran.

\section{Conflicts of interest}

There are no conflicts of interest. 


\section{REFERENCES}

1. Tezel H, Atalayin C, Kayrak G. Replantation after traumatic avulsion. Eur J Dent 2013;7:229-32.

2. Andreasen JO, Andreasen FM, Andersson L. Textbook and Color Atlas of Traumatic Injuries to the Teeth. $4^{\text {th }}$ ed. Copenhagen: Blackwell Munksgaard; 2007. p. 14-8, 444, 450-8.

3. Pohl Y, Filippi A, Kirschner H. Results after replantation of avulsed permanent teeth. I. Endodontic considerations. Dent Traumatol 2005;21:80-92.

4. McTigue DJ. Managing traumatic injuries in the young permanent dentition. In: Pinkham JR, Casassimo PS, McTigue D, Fields HW, Nowak AJ, editors. Pediatric Dentistry, Infancy through Adolescence. $4^{\text {th }}$ ed. USA: Elsevire Saunders; 2005. p. 604.

5. Arikan F, Becerik S, Sonmez S, Gurhan I. Effect of platelet-rich plasma on gingival and periodontal ligament fibroblasts: New in vitro growth assay. Braz J Oral Sci 2007;23:1432-7.

6. Fréchette JP, Martineau I, Gagnon G. Platelet-rich plasmas: Growth factor content and roles in wound healing. J Dent Res 2005;84:434-9.

7. Ntounis A, Geurs N, Vassilopoulos P, Reddy M. Clinical assessment of bone quality of human extraction sockets after conversion with growth factors. Int J Oral Maxillofac Implants 2015;30:196-201.

8. Wang HL, Avila G. Platelet rich plasma: Myth or reality? Eur J Dent 2007;1:192-4

9. Choi SH, Kim CK, Cho KS, Huh JS, Sorensen RG, Wozney JM, et al. Effect of recombinant human bone morphogenetic protein-2/absorbable collagen sponge (rhBMP-2/ACS) on healing in 3-wall intrabony defects in dogs. J Periodontol 2002;73:63-72.

10. Carlson NE, Roach RB Jr. Platelet-rich plasma: Clinical applications in dentistry. J Am Dent Assoc 2002;133:1383-6.

11. Marx RE. Platelet-rich plasma: Evidence to support its use. J Oral Maxillofac Surg 2004;62:489-96.

12. Slapnicka J, Fassmann A, Strasak L, Augustin P, Vanek J. Effects of activated and nonactivated platelet-rich plasma on proliferation of human osteoblasts in vitro. J Oral Maxillofac Surg 2008;66:297-301.

13. Ogino Y, Ayukawa Y, Kukita T, Koyano K. The contribution of platelet-derived growth factor, transforming growth factor-beta 1, and insulin-like growth factor-I in platelet-rich plasma to the proliferation of osteoblast-like cells. Oral Surg Oral Med Oral Pathol Oral Radiol Endod 2006;101:724-9.

14. Cáceres M, Hidalgo R, Sanz A, Martínez J, Riera P, Smith PC. Effect of platelet-rich plasma on cell adhesion, cell migration, and myofibroblastic differentiation in human gingival fibroblasts. J Periodontol 2008;79:714-20.

15. Arnoczky SP, Delos D, Rodeo SA. What is platelet-rich plasma? Oper Tech Sports Med 2011;19:142-8.
16. Marx RE. Platelet-rich plasma (PRP): What is PRP and what is not PRP? Implant Dent 2001;10:225-8.

17. Graziani F, Ivanovski S, Cei S, Ducci F, Tonetti M, Gabriele M. The in vitro effect of different PRP concentrations on osteoblasts and fibroblasts. Clin Oral Implants Res 2006;17:212-9.

18. Sánchez AR, Sheridan PJ, Kupp LI. Is platelet-rich plasma the perfect enhancement factor? A current review. Int J Oral Maxillofac Implants 2003;18:93-103.

19. Kawase T, Okuda K, Saito $\mathrm{Y}$, Yoshie H. In vitro evidence that the biological effects of platelet-rich plasma on periodontal ligament cells is not mediated solely by constituent transforming-growth factor-beta or platelet-derived growth factor. J Periodontol 2005;76:760-7.

20. Choi BH, Im CJ, Huh JY, Suh JJ, Lee SH. Effect of platelet-rich plasma on bone regeneration in autogenous bone graft. Int J Oral Maxillofac Surg 2004;33:56-9.

21. Cenni E, Ciapetti G, Pagani S, Perut F, Giunti A, Baldini N. Effects of activated platelet concentrates on human primary cultures of fibroblasts and osteoblasts. J Periodontol 2005;76:323-8.

22. Weibrich G, Kleis WK, Hafner G. Growth factor levels in the platelet-rich plasma produced by 2 different methods: Curasan-type PRP kit versus PCCS PRP system. Int J Oral Maxillofac Implants 2002;17:184-90.

23. Choi BH, Zhu SJ, Kim BY, Huh JY, Lee SH, Jung JH. Effect of platelet-rich plasma (PRP) concentration on the viability and proliferation of alveolar bone cells: An in vitro study. Int J Oral Maxillofac Surg 2005;34:420-4.

24. Setiawati EM. Natural growth factor: Platelet rich plasma stimulates proliferation of fibroblast cell culture. Indones J Trop Infect Dis 2010;1:102-4.

25. Marx RE, Carlson ER, Eichstaedt RM, Schimmele SR, Strauss JE Georgeff KR. Platelet-rich plasma: Growth factor enhancement for bone grafts. Oral Surg Oral Med Oral Pathol Oral Radiol Endod 1998;85:638-46.

26. Creeper F, Lichanska AM, Marshall RI, Seymour GJ, Ivanovski S. The effect of platelet-rich plasma on osteoblast and periodontal ligament cell migration, proliferation and differentiation. J Periodontal Res 2009;44:258-65

27. Han J, Meng HX, Tang JM, Li SL, Tang Y, Chen ZB. The effect of different platelet-rich plasma concentrations on proliferation and differentiation of human periodontal ligament cells in vitro. Cell Prolif 2007;40:241-52.

28. Dugrillon A, Eichler H, Kern S, Klüter H. Autologous concentrated platelet-rich plasma (cPRP) for local application in bone regeneration. Int J Oral Maxillofac Surg 2002;31:615-9.

29. Landesberg R, Roy M, Glickman RS. Quantification of growth factor levels using a simplified method of platelet-rich plasma gel preparation. J Oral Maxillofac Surg 2000;58:297-300. 